

\title{
Extensão rural e políticas públicas de inclusão produtiva da agricultura familiar no Brasil: (des)conexões entre referenciais, ideias e práticas
}

\author{
Rural extension and public policies for the \\ productive inclusion of family agriculture in \\ Brazil: (dis)connections between references, \\ ideas and practices
}

\author{
Diego Neves de Sousa* | Paulo André Niederle** \\ http://dx.doi.org/10.51861/ded.dmvu.2.019 \\ Recebido em 8 de janeiro de 2021. Aceito em 23 de abril de 2021.
}

\begin{abstract}
Resumo
O termo "inclusão produtiva" foi amplamente incorporado pelo Estado brasileiro no começo dos anos 2000. No entanto, isto se deu sem que os policymakers se preocupassem com a construção de uma definição precisa para o mesmo, o que levou à proliferação de diferentes interpretações e, em virtude disso, distorções na formulação, implementação, execução e avaliação das políticas públicas ditas de inclusão produtiva. A partir de um diálogo com a abordagem cognitiva de análise de políticas públicas (Muller, 2008), este artigo analisa se o referencial de inclusão produtiva que orienta as políticas para a agricultura familiar converge com as ideais e práticas desenvolvidas pelos extensionistas rurais que intermedeiam o acesso às mesmas. Os dados provêm de pesquisa documental e entrevistas com extensionistas do Estado do Tocantins realizadas entre maio e agosto de 2018 . Os resultados demonstram que as políticas para a agricultura familiar são orientadas por diferentes referenciais de inclusão, o que força os mediadores a articulá-las e torná-las coerentes para o público beneficiário. No entanto, estes referenciais não coincidem com as ideias e práticas dos extensionistas envolvidos nos processos de tradução das políticas para os diferentes grupos de agricultores familiares, o que acentua as desconexões entre as intenções das políticas e seus efeitos.
\end{abstract}

Palavras-chave: Exclusão social. Desenvolvimento rural. Agentes extensionistas.

\begin{abstract}
The term "productive inclusion" was widely incorporated by the Brazilian State in the early 2000s. However, this happened without policymakers being concerned with building a precise definition for it, resulting in the proliferation of different interpretations and, as a consequence, distortions in the formulation, implementation, execution and evaluation of the public policies for productive inclusion. Based on a dialogue with the cognitive approach to public policy analysis (Muller, 2008), this article analyzes whether the referential of productive inclusion that guides policies for family farming converges with the ideals and practices developed by rural extension agents who mediate the access to them. The data comes from documentary research and interviews carried out from May to August 2018 with extension agents from the State of Tocantins. Results show that policies for family farming are guided by different "referentials" of inclusion, which forces mediators to articulate them and make them coherent for the public. However, these referentials do not coincide with the ideas and practices of extension agents involved in the processes of translating policies for different groups of family farmers, which accentuates the disconnections between policy intentions and their effects.
\end{abstract}

Keywords: Social exclusion. Rural development. Extension agents.

\footnotetext{
* Diego Neves de Sousa

Analista da Embrapa Pesca e Agricultura. Prolongamento da Av. NS 10, cruzamento com a Av. LO 18 Sentido Norte Loteamento - Água Fria, Palmas - Tocantins. CEP: 77008-900.

ORCID: https://orcid.org/0000-0003-3124-5150.E-mail: diego.sousa@embrapa.br

** Paulo André Niederle

Professor e atual Coordenador do Programa de Pós-Graduação em Sociologia (PPGS) da Universidade Federal do Rio Grande do Sul (UFRGS). Avenida Bento Gonçalves, 9500, IFCH-Agronomia. Porto Alegre, Rio Grande do Sul. CEP: $91509-900$.

ORCID: https://orcid.org/0000-0002-7566-5467.E-mail: paulo.niederle@ufrgs.br
} 


\section{INTRODUÇÃO}

Em 2003, o Brasil apresentava 41,8 milhões de pessoas em situação de pobreza e 12,9 milhóes em extrema pobreza, o que representava, respectivamente, $23 \%$ e $7 \%$ da sua população total. Apenas uma década depois, em 2014, estes números despencaram para 14,1 milhões (7\%) e 5,2 milhões, (2,6\%), respectivamente. Em virtude da magnitude destas mudanças, as políticas brasileiras de combate à pobreza se tornaram objeto de crescente interesse internacional e algumas delas chegaram a ser inclusive difundidas para outros países (SABOURIN \& GRISA, 2018). No entanto, apesar de importante, a redução da pobreza nas áreas rurais não se deu com a mesma magnitude. No período acima referido, enquanto nas áreas urbanas o número de pobres passou de 33,4 para 7,7 milhôes de pessoas, e o de extremamente pobres caiu de 6,5 para 2,5 milhôes, no meio rural esta redução foi, respectivamente, de 8,4 para 3,5 milhôes, e de 6,4 para 2,7 milhões (AQUINO \& NASCIMENTO, 2019).

A crise econômica e política que o país passou a vivenciar a partir de2015 resultou em um rápido crescimento da pobreza e, sobretudo, da extrema pobreza, a qual, em 2019, já atingia novamente 13,2milhóes de brasileiros. No entanto, a população rural parece estar sendo proporcionalmente menos afetada que a urbana. Enquanto as taxas de crescimento da pobreza e da pobreza extrema da população urbana entre 2013 e 2017 foram de $25,5 \%$ e $116,4 \%$, na população rural elas corresponderam a $-0,08 \%$ e $57,9 \%$, respectivamente (IBGE, 2018). Esta relativa inércia da pobreza nas áreas rurais revela que o fenômeno é mais difícil de ser enfrentado, sobretudo em virtude da dificuldade das políticas para identificar e chegar até os pobres rurais (AQUINO \& NASCIMENTO, 2019). Entretanto, também demonstra que, uma vez que as políticas chegam, parecem ter efeitos mais duradouros ao longo do tempo, o que pode estar associado ao tipo de ação pública destinada às áreas rurais e, em particular, aos agricultores familiares.

As políticas de transferência de renda similares ao Programa Bolsa Família tiveram forte impacto na redução da pobreza urbana e rural (REGO \& PINZANI, 2013). Não obstante, para além da superação da pobreza monetária, a efetiva inclusão econômica dos beneficiários destas transferências dependia de outras políticas. Com efeito, entre 2003 e 2014, as políticas de emprego e expansão dos salários foram centrais no setor urbano, levando a uma redução mais rápida da pobreza nas cidades do que no meio rural. Contudo, no atual contexto de crise econômica e desemprego, a extrema pobreza urbana tem crescido numa velocidade mais rápida. Isto sugere que, no meio rural, apesar de mais lento e difícil, pode ter havido um processo mais consistente de "inclusão produtiva" dos pequenos agricultores por meio de políticas que provocaram alteraçóes estruturais nas suas condições de reprodução social. 
O termo "inclusão produtiva” se tornou um mantra para a ação do Estado no meio rural brasileiro. Para superar a miséria, assegurar renda, sustentar os níveis de emprego, fortalecer as comunidades, reduzir o peso das políticas sociais, e até mesmo para salvar os recursos naturais de um suposto (e criticável) "círculo vicioso da pobreza", a inclusão produtiva tornou-se uma espécie de passe partout na ação pública. No entanto, esta expressão comporta uma pluralidade de significados, os quais respondem a distintos referenciais de desenvolvimento. No caso do meio rural, enquanto alguns significados se associam a uma lógica modernizante centrada na capacidade dos agricultores em oferecer respostas produtivas convencionais (apostando na melhoria da capacidade tecnológica e empreendedora de um agricultor profissionalizado) (NAVARRO; \&PEDROSO, 2014), outros sustentam experiências alternativas que sugerem a emergência de um novo rural multifuncional e pós-produtivista (PLOEG, 2004; SABOURIN, 2014; WANDERLEY, 2014).

Um dos principais problemas talvez seja o fato de que a noção de inclusão produtiva passou a balizar a construção de inúmeras políticas públicas sem que os policymakers se preocupassem com o seu significado. Assim, a mesma se tornou objeto de interpretações que criaram distorçốes na formulação, implementação, execução e mesmo na avaliação das políticas. Isto transferiu uma enorme responsabilidade para os mediadores sociais que atuaram diretamente nos processos de "tradução" das políticas para seus beneficiários. A partir de um diálogo com a abordagem cognitiva de análise de políticas públicas (JOBERT \& MULLER, 1987; ROE, 1994; SCHMIDT \& RADAELLI, 2004; RADAELLI, 2006), a qual destaca a importância das ideias e narrativas na construção de "referenciais" de ação pública, este artigo analisa estas (des)conexões entre o referencial das políticas de inclusão produtiva da agricultura familiar e as ideais dos extensionistas rurais que intermedeiam o acesso às mesmas por diferentes grupos de agricultores familiares do estado do Tocantins.

O artigo está estruturado em seis seções, além desta introdução. A segunda seção contextualiza a construção das políticas públicas para os agricultores familiares brasileiros. Em seguida é apresentado o problema de pesquisa e o percurso metodológico. A quarta seção discute a abordagem cognitiva e sua relação com a análise de políticas públicas. A seção subsequente discute os principais resultados do estudo. Por fim, as consideraçôes finais sintetizam as principais conclusóes e apontam para novas questóes nesta agenda de pesquisa. 


\section{A CONSTRUÇÃO DAS POLİTICAS PÚBLICAS PARA A AGRICUL- TURA FAMILIAR BRASILEIRA}

As políticas públicas para a agricultura brasileira estiveram historicamente ancoradas em uma narrativa que destaca a necessidade de levar o progresso técnico e a modernidade para o meio rural (KAGEYAMA \& GRAZIANO DA SILVA, 1983; MIELITZ NETTO, 2011; GRISA \& PORTO, 2015). Esta ideia produziu efeitos na organização do serviço de assistência técnica e extensão rural, o qual foi concebido numa perspectiva de comunicação unilateral, tendo o agricultor apenas como um receptor dos pacotes tecnológicos transferidos pelos técnicos, principalmente pelos profissionais provenientes das ciências agrárias (COELHO, 2005). O papel destes mediadores sociais era propagar o desenvolvimento de uma agricultura altamente produtiva, o que também implicava em selecionar os agricultores que poderiam embarcar em tal odisseia e os que deveriam ser excluídos.

Como consequência da institucionalização desse referencial modernizante e difusionista, ocultaram-se os problemas gerados pelo progresso, principalmente no que tange às desigualdades sociais que ele acentuou (MIELITZ NETTO, 2011; GRISA, 2012). Os agricultores familiares “periféricos” foram relegados pelo Estado e, "lá na ponta”, pelos mediadores sociais, haja vista que tanto os referenciais das políticas agrícolas quanto as ideias e práticas dos extensionistas seguiram uma lógica modernizante e produtivista que favoreceu, sobretudo, a expansão da produção de commodities no Sul e Sudeste do país (SABOURIN, 2017).

Por sua vez, a agricultura e os agricultores da região Norte, para os quais os modos de vida e de produção são muito diferenciados daqueles que orientam o referencial das políticas de modernização, apresentam dificuldades em se adequar à racionalidade que rege as políticas agrícolas (MEDINA, NOVAES \& TEIXEIRA, 2017). Este é o caso de aproximadamente $45 \mathrm{mil}$ agricultores familiares do Tocantins (IBGE, 2017), os quais enfrentam múltiplas precariedades para desenvolver suas atividades produtivas:limitaçóes nas estruturas de produção e dificuldades no acesso ao crédito, à assistência técnica e aos mercados (PETARLY et al., 2016); deficiências nas estruturas de processamento e distribuição; falta de recursos dos municípios para serviços de inspeção sanitária animal; bem como baixo nível de organização social e produtiva (SOUSA et al., 2019).

Esta situação começou a mudar quando, a partir dos anos 1990, "novas ideias, interesses e narrativas passaram a permear as açóes do Estado brasileiro" (SOLDERA, 2017, p. 20). Contrariando as teses sobre o desaparecimento da pequena produção frente ao avanço do capitalismo no campo, o reconhecimento da categoria sociopolítica da "agricultura familiar" influen- 
ciou a concepção de novas políticas de desenvolvimento rural (NIEDERLE, FIALHO \& CONTERATO, 2014; SCHNEIDER, 2014; PICOLOTTO, 2014; ESQUERDO \& BERGAMASCO, 2014; GRISA \& SCHNEIDER, 2014). Dentre as principais ações governamentais, destacam-se a criação do Programa Nacional de Fortalecimento da Agricultura Familiar (Pronaf) em 1995, do Ministério do Desenvolvimento Agrário (MDA) em 1999, do Programa de Aquisição de Alimentos (PAA) em 2003, da Lei da Agricultura Familiar em 2006, e as alterações ocorridas no Programa Nacional de Alimentação Escolar (Pnae) no ano de 2009, e na Política Nacional de Assistência Técnica e Extensão Rural (Pnater) em 2010.

Grisa e Schneider (2014) classificaram as políticas públicas brasileiras para a agricultura familiar em três geraçôes de acordo com diferentes "referenciais" de ação pública. Como sugerem os autores, na primeira geração, destacou-se o Pronaf, que foi a primeira política agrícola do país direcionada especificamente aos agricultores familiares. Inicialmente, o Pronaf visava financiar os agricultores "em transição", ou seja, aqueles que se encontravam parcialmente inseridos nos circuitos de inovação tecnológica e de mercado, tendo em vista consolidá-los como agricultores familiares altamente produtivos (FAO/INCRA, 1994). Em virtude disso, o programa privilegiou modelos produtivos convencionais com baixa capacidade de absorção de mão de obra, alto grau de especialização e integrados aos mercados convencionais (GAZOLLA \& SCHNEIDER, 2013). Isto refletiu no maior volume de investimentos nas regióes Sul e Sudeste do país, onde o processo de modernização da agricultura havia avançado mais rapidamente desde a década de 1960.

A segunda geração de políticas surgiu diante dos efeitos negativos e das insuficiências verificadas pela política de crédito rural. Ela demarca a criação de um conjunto de políticas socioassistenciais para mitigar a pobreza rural não retratada pelas políticas orientadas por um referencial agrícola e agrário (GRISA \& SCHNEIDER, 2014). Cabe notar que, nas estatísticas oficiais, a agricultura familiar aparece como segundo maior grupo de indivíduos em situação de extrema pobreza no campo, ficando atrás somente do grupo de famílias sem inserção produtiva (DEL GROSSI, 2012), sendo que as regióes Norte e Nordeste concentram o maior número de agricultores em condiçôes de extrema pobreza (MEDINA, NOVAES \& TEIXEIRA, 2017). Para Cazella et al. (2016), as políticas produtivas estão mais centradas nas camadas de agricultores "intermediários” e "consolidados" que já estão inseridos nos mercados agroalimentares. Assim, segundo os autores, "sobram" para os agricultores pobres as políticas socioassistenciais, as quais, por sua vez, não se integram com as políticas agrícolas. 
As políticas sociais de transferência de renda foram fundamentais para a redução da pobreza, mas se mostraram menos exitosas na promoção da inclusão produtiva dos agricultores. Segundo a literatura, resultados mais evidentes neste sentido estão associados à terceira geração de políticas para a agricultura familiar, a qual destaca a construção de mercados para a promoção da segurança alimentar e a sustentabilidade ambiental (GRISA \& SCHNEIDER, 2014). Neste caso, a política que teve maior visibilidade foi o Programa de Aquisição de Alimentos (PAA), criado em 2003 para articular a compra de produtos provenientes da agricultura familiar com açóes de Segurança Alimentar e Nutricional (SAN) para populaçôes vulneráveis. O programa ganhou relevância em face do seu efeito na dinamização das economias locais e no fortalecimento das organizações coletivas da agricultura familiar.

A novidade produzida pelo PAA fez com que, em várias políticas públicas para a agricultura familiar, a ideia de inclusão produtiva passasse a ser estreitamente associada à construção de novos mercados, com destaque para os chamados "mercados institucionais" criados pelas compras governamentais (NIEDERLE, 2017). Com efeito, em 2009, com algumas similaridades com o modo de operação do PAA, o Programa Nacional de Alimentação Escolar foi redesenhado e passou a exigir que, pelo menos, $30 \%$ dos recursos governamentais para a alimentação escolar fossem utilizados para aquisição de produtos provenientes de agricultores familiares e de seus empreendimentos coletivos (BRASIL, 2009).

\section{O PROBLEMA DE PESQUISA E O PERCURSO METODOLÓGICO}

A adequação das estratégias de inclusão produtiva à formação de políticas adequadas para diferentes grupos de agricultores implica em importante desafio para os extensionistas, haja vista que estes são portadores de conhecimentos que podem contribuir na tradução de informações e, assim, articular as ações públicas à realidade de cada grupo beneficiário. Com efeito, os próprios extensionistas atribuem a si mesmos um papel "emancipador", o qual é fomentado pela possibilidade de "transferência” de outras visóes de mundo (materializada nas práticas dos agricultores) e pela incorporação de saberes distintos daqueles de que o grupo mediado se encontra dotado (NEVES, 2010). Por outro lado, também se verifica, por vezes, as dificuldades encontradas por eles decorrentes da falta de articulação entre as políticas públicas em seus vários níveis, o que pode acarretar em "erros de tradução" (AQUINO et al., 2017).

Para além da desarticulação entre os diferentes tipos de políticas destacados acima (agrícolas, sociais e de segurança alimentar), o principal problema 
talvez seja o fato de que a noção de inclusão produtiva passou a balizá-las sem que os formuladores das mesmas se preocupassem com o que ela realmente representa, ou seja, seu significado. O que esperar, portanto, dos extensionistas rurais que atuam diretamente com os beneficiários das políticas no meio rural, os quais têm que traduzir os referenciais que orientam as política sem açóes concretas? A partir desta questão, este artigo explora o seguinte problema de pesquisa: em que medida os "referenciais" que orientam as políticas de inclusão produtiva convergem com as ideias e as práticas dos extensionistas rurais implicados nos processos de "tradução" das políticas públicas para os agricultores familiares do Tocantins?

A pesquisa da qual se origina este artigo partiu da premissa de que aquilo que as políticas incentivam não corresponde às expectativas e práticas dos extensionistas. Com efeito, o fato das políticas serem orientadas por diferentes referenciais confere a eles a responsabilidade de traduzi-las e articulá-las para torná-las coerentes para os diferentes grupos de agricultores familiares: assentados dos programas de reforma agrária, extrativistas, ribeirinhos, indígenas, quilombolas, pescadores artesanais, aquicultores familiares, povos da floresta, seringueiros, etc. Parte-se do pressuposto que, neste processo de tradução, existem inúmeras reinterpretações e "traições", de modo que os extensionistas tentam ajustar o conteúdo das políticas às suas distintas concepções de inclusão produtiva.

De natureza eminentemente qualitativa, a pesquisa envolveu duas técnicas de coleta de dados: entrevistas semiestruturadas e análise documental das normas que regem as políticas públicas. No caso das entrevistas, estas foram realizadas entre os meses de maio a agosto de 2018 com 39 extensionistas rurais que atuam em 22 municípios do Tocantins(Figura 1). A concentração de entrevistas no município de Palmas, capital do Tocantins, é devido onde estão as sedes das principais instituiçóes públicas e privadas do estado.

Optou-se pelos extensionistas porque são considerados como mediadores centrais das políticas públicas, uma vez que têm maior contato com os agricultores devido à capilaridade dos escritórios da empresa pública de extensão rural no estado do Tocantins e também por ela ser executora de diversas políticas públicas.

Escolheu-se o Tocantins para ser objeto empírico desta pesquisa porque, apesar (ou em virtude da) da pujança do agronegócio,o estado continua a ser um dos mais pobres do país (OLIVEIRA, PIFFER \& STRASSBURG, 2017). Localizado no coração do Matopiba, "última fronteira agrícola brasileira”, e apresentando níveis elevados de produtividade agrícola, com destaque para a pecuária e a soja, o estado possui altos índices de pobreza urbana e rural, o que é fruto da alta concentração da riqueza produzida pelo modelo 
de desenvolvimento agroexportador privilegiado pelas elites locais e nacionais (FAVARETTO, 2019).O discurso desenvolvimentista prevalecente na região, herança do modelo militar de ocupação predatória da Amazônia Legal, acarretou na emergência de grandes empreendimentos de infraestrutura para o agronegócio, os quais se tornaram a mola propulsora da econo-

Figura 1 - Localização dos municípios em que os mediadores entrevistados residem no Tocantins.

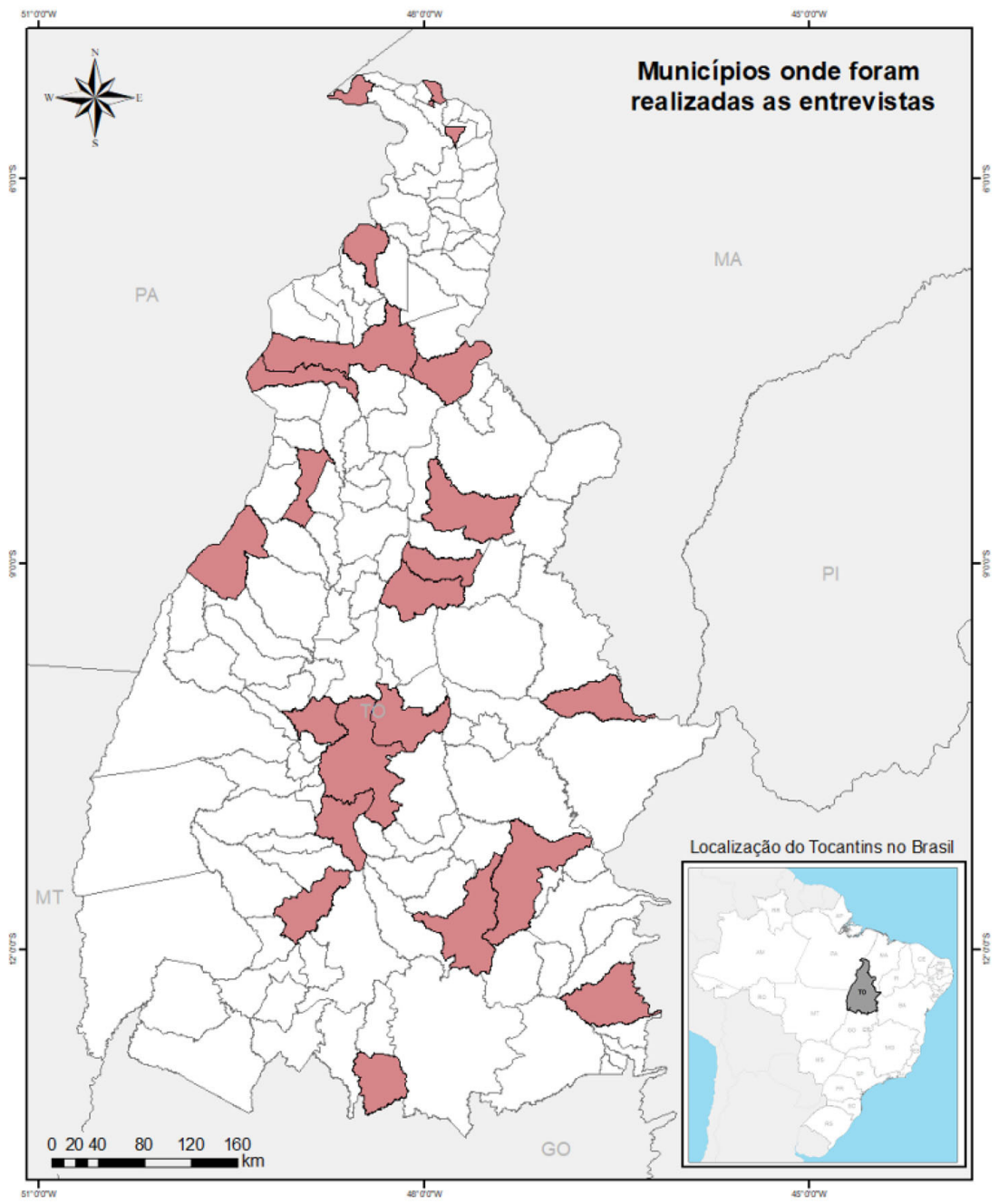

Fonte: Dados da pesquisa (2018). Elaborado por Marta Eichemberger Ummus/Embrapa. 
mia regional, mas afetaram sobremaneira a reprodução social de povos originários e tradicionais que têm seus modos de vida atrelados à dinâmica da natureza, à diversidade de produtos da sociobiodiversidade e à manutenção dos biomas onde estão suas comunidades (SOUSA, 2019).

Os repertórios culturais específicos e diversificados dos povos tradicionais do estado do Tocantins estão associados à diversidade de biomas (cerrado, floresta amazônica e pantanal), de produtos da sociobiodiversidade (coco babaçu, pequi, buriti, mangaba etc.) e de povos originários e tradicionais (indígenas, quilombolas, quebradeiras de coco etc.) (MENESTRINHO \& PARENTE, 2011). A formação do rural tocantinense passou por significativas transformaçốes, principalmente para a população de ribeirinhos, pescadores artesanais e de agricultores familiares que foram impactados por grandes empreendimentos e que tiveram que ser reassentados em outras localidades.

Em relação aos públicos da agricultura familiar tocantinense Sousa (2019) constatou que os assentados de reforma agrária foram os que mais se beneficiaram das políticas públicas, enquanto que os quilombolas e os indígenas foram os mais preteridos, pois são considerados os mais afetados por problemas sociais no meio rural, por viverem em territórios com áreas aquém de suas necessidades e por não estarem dotados de aparatos jurídico-formais e itinerários técnicos que lhes assegurem a regularização territorial, o que culmina quase sempre em conflitos agrários e em processos de exclusão.

\section{O PAPEL DAS IDEIAS E O PROTAGONISMO DOS ATORES SOCIAIS: A CONTRIBUIÇÃO DA ABORDAGEM COGNITIVA}

Incorporada pelas ciências sociais brasileiras nos últimos anos (GRISA, 2012; LUKIC \& TOMAZINI, 2013; FRANÇA, 2016), a abordagem cognitiva enfatiza o papel das ideias e das argumentaçôes na formulação das políticas públicas e o protagonismo dos atores sociais na produção de representaçôes sobre os problemas sociais e de respostas para os mesmos. Esta abordagem compreende a ação pública não como mero processo de tomada de decisão, mas como processo por meio do qual determinada sociedade constrói sua relação com o mundo a partir de suas ideias e argumentaçóes (MULLER, 2005). A originalidade da abordagem está na forma como analisa o modo como os diferentes grupos de atores compreendem o mundo ao agir na realidade social e, assim, propóem soluções aos gargalos decorrentes da ação pública (SUREL, 2000).

Diferentemente das abordagens tradicionais de análise de políticas públicas, as quais não consideravam os elementos cognitivos como variável explicativa primordial (GRISA, 2012), a abordagem cognitiva busca apreender as 
políticas públicas como matrizes cognitivas e normativas. Ao reforçar o interesse pelos sistemas de interpretação do real no interior dos quais diversos atores inscrevem sua ação, a abordagem privilegia as formas como apreendemos subjetivamente o mundo social. A partir dela é possível entender como são construídos os referenciais que orientam as políticas públicas e como estes interagem com as ideias sustentadas pelos mediadores destas políticas acerca da inclusão produtiva dos agricultores familiares.

Para Grisa (2012), a preocupação principal desta abordagem está centrada na atuação dos atores do processo diante da construção de ideias e negociaçôes entre os formuladores diretos das políticas públicas, incluindo os conflitos emergentes. Os modelos inspirados na argumentação de ideias têm em comum a convicção de que a política pública é "construída por palavras”, as quais devem ser tomadas em conta por quem está analisando-as (MAJONE, 2005). Para tanto, pressupóe-se o uso de diversos enfoques que resgatam a linguagem como elemento determinante. Blandón (2014) afirma que a análise argumentativa de política pública focaliza o papel crucial da linguagem, da argumentação, da retórica e das histórias abordadas no decorrer do debate, assim como a estruturação do marco deliberativo no qual se formula tal política. Configura-se, assim, tanto para os policymakers quanto aos demais atores interessados nas decisões políticas, o desafio de compartilharem da significação dos argumentos e dos símbolos em suas respectivas funções (GOTTWEIS, 2007).

A produção de referenciais é alimentada, ao mesmo tempo, por processos de tomada de palavra (produção do sentido) e de tomada de poder (estruturação de um campo de forças), como apontam Muller e Yves (2002). A "virada argumentativa" (argumentativeturn) nos estudos sobre políticas públicas destaca as práticas discursivas dos atores partícipes do processo e busca identificar os interesses materiais e ideais que são enraizados nas disputas sociais. Assim, teorias que têm como preocupação central a dimensão do discurso e da argumentação fornecem importantes contribuições para a compreensão não apenas do papel dos atores, suas construçôes de sentidos e representaçóes sociais, mas também as disputas entre os mesmos na estruturação das políticas públicas (JESSOP, 2009).

\section{RESULTADOS E DISCUSSÃO}

O primeiro passo da pesquisa foi identificar as políticas públicas para a agricultura familiar que são consideradas "de inclusão produtiva” pelos extensionistas. Dentre os 39 extensionistas entrevistados, $88,8 \%$ citaram pelo menos uma política e destes $70 \%$ mencionaram como principais políticas federais: 
Pnater, Pronaf, PAA e Pnae. Além disso, ratificou-se a baixa sinergia das políticas sociais em relação à inclusão produtiva, haja vista que nenhuma política de transferência de renda ou assistência social foi mencionada pelos extensionistas. Assim, apesar de existirem relatos na literatura de que áreas rurais mais empobrecidas do país com acesso as políticas sociais tiveram melhorias em seus indicadores de desenvolvimento, as quais provavelmente não teriam sido alcançadas somente por meio de políticas agrícolas (primeira geração) ou de segurança alimentar (terceira geração), o que se nota é que os extensionistas rurais não identificam potencial de inclusão produtiva nas políticas de cunho socioassistencial como o Programa Bolsa Família.

Os extensionistas mencionam a Pnater como a principal política de inclusão produtiva, o que coloca em evidência a sua própria atuação. Além disso,é considerada uma política que potencializa as demais políticas de desenvolvimento rural como é retratada nas narrativas por alguns mediadores, por exemplo: "Basicamente, a política pública de extensão rural tem a base para o meio rural e ela também dinamiza outras políticas, tipo PAA, Compra Direta e a política de crédito rural” (EX19, 2018). Muitas das vezes, essa relação está também associada à transferência de conhecimentos e de tecnologias por meio de profissionais do serviço de assistência técnica que buscam traduzir simultaneamente diferentes políticas públicas.

Na sequência foram citados PAA, Pnae e Pronaf, os quais são programas cujo acesso é, em maior ou menor grau, intermediado ou assessorado pelos extensionistas rurais. No caso do PAA e do Pnae, estes atores atuam como assessores técnicos para fomentar a participação dos agricultores e de suas organizações em Chamadas Públicas. O papel das Compras Governamentais se destaca por ser um mercado garantido para propagar o escoamento da produção dos agricultores familiares, além de ter uma função social representativa ao proporcionar a doação de alimentos para grupos em situação de vulnerabilidade e, com isso, contribuindo para a segurança alimentar desses indivíduos. Na opinião de um mediador a ideia central das Compras governamentais é que o Estado

[...] doe para o próprio município para ser comercializado, para ser aproveitado em escolas, creches e instituiçốes. Então, você cria um ciclo virtuoso, ou seja, o produtor produz, fornece o alimento para própria comunidade e esse alimento vai ser usado nas escolas e instituiçốes. Então, ele não só tem um viés econômico, mas um viés social muito forte (EX22, 2018).

Já em relação ao Pronaf, os extensionistas participam diretamente na elaboração do projeto de crédito rural. Esta compreensão ratifica o modelo historicamente vigente de atuação da extensão rural para promoção da modernização, associando os instrumentos mais tradicionais de política agrícola 
(crédito e comercialização) com a atuação das entidades de extensão como promotoras de mudanças tecnológicas. Isto demonstra que os extensionistas associam a ideia de inclusão produtiva numa perspectiva instrumental sobre transferência de tecnologia e como esta política de crédito pode potencializar o acesso do agricultor a equipamentos, máquinas e artefatos tecnológicos, ocasionando, assim, a modernização do seu sistema produtivo. Para tanto, comprava-se na fala de um mediador que relata que "têm alguns casos de agricultores que mexe com horta, depois que acessaram ao Pronaf, adquiriram um tratorzinho, um complemento, uma caminhonetinha para poder trazer a mercadoria para a feira” (EX28, 2018).

Esta compreensão também é ratificada pela citação das políticas de Fomento e do Plano ABC (Agricultura de Baixa Emissão de Carbono). O Programa de Fomento é um desdobramento do extinto Programa Brasil Sem Miséria para a redução da pobreza no país, que atualmente é de responsabilidade do Instituto de Desenvolvimento Rural do Tocantins (Ruraltins), que o executa no estado oferecendo aos beneficiários o serviço de assistência técnica gratuita e a transferência de recursos financeiros no valor de $\mathrm{R} \$ 2.400,00$ para a compra de insumos e equipamentos agrícolas. Para um extensionista esta "é uma política pública excelente e que gera resultados para quem está abaixo da linha da miséria, da linha da pobreza" (EX12, 2018).

Já o Plano $\mathrm{ABC}$ visa desenvolver práticas que contribuam para a redução da emissão dos gases de efeito estufa e que têm os agricultores familiares como um dos potenciais públicos para alcançar as metas do governo. No Tocantins, esta política é disseminada pelos extensionistas rurais em parceria da Empresa Brasileira de Pesquisa e Agropecuária (Embrapa) através de projetos de Pesquisa, Desenvolvimento \& Inovação (PD\&I) e de Transferência de Tecnologia (TT) que versam sobre essa temática. O ABC é uma política bastante direcionada para grandes produtores, mas tem percebido que no Tocantins um número crescente de pequenos produtores passou também a adotar as tecnologias disponíveis. Por sua vez, um extensionista também notou resultados significativos no decorrer de suas intervençóes no meio rural tocantinense a partir da execução das açôes do Plano ABC, na qual a contribuição primordial é referente a quantidade de tecnologias disponíveis para o agricultor familiar. "A gente tem muita tecnologia, o $\mathrm{ABC}$ é um exemplo disso, tem muita tecnologia que melhora a eficiência produtiva. Eu acho que esse para mim é o principal desafio hoje, o de melhorar a eficiência produtiva da agricultura familiar” (EX12, 2018). Por essa razão, é imprescindível que hajam ações apropriadas para o contexto da agricultura familiar no âmbito do $\mathrm{ABC}$, porque tem que ser pensado 
[...] a questão da sustentabilidade dentro da agricultura familiar, a gente fala muito em diversificação da produção. Enfim, mas eu acho que essa questão ambiental ela não pode ser debatida só de forma assim protecionista da natureza, o agricultor tem que compreender a necessidade da preservação, a importância da preservação e não só o grande. Mas acho que o pequeno é também responsável por essa produção sustentável, eu acho que tem muita área ainda dentro da agricultura familiar que ela é mal aproveitada e que as políticas dentro do $\mathrm{ABC}$ vêm ao encontro do que já vem trabalhando o Pronaf, a assistência técnica e o PAA (EX12, 2018).

A menção dessas políticas pelos extensionistas denota o peso que os mesmos conferem aos processos de modernização tecnológica como caminho para a inclusão produtiva, o que é mais condizente com a visão esboçada por autores como Alves (2001) e Navarro e Pedroso (2014). De acordo com os mesmos, a "vocação produtiva" estaria confinada a pequena parcela de agricultores mais capitalizados, enquanto restariam aos pobres rurais políticas sociais como se eles não chegassem a progredir economicamente.

Por terem uma visão mais instrumental sobre os processos de transferência de tecnologias, os extensionistas compreendem que o Pronaf tem forte ligação com a modernização da agricultura. Esta compreensão está fortemente conectada ao referencial do Pronaf, haja vista que três das nove diretrizes do Programa referem-se aos aspectos da modernização da propriedade rural por meio da aplicação de tecnologias financiadas pelo crédito rural. No entanto, na normativa do Pronaf não é encontrada nenhum aspecto direto que remeta ao tema da inclusão produtiva. Apesar de algumas modalidades específicas do Programa apontarem para a inclusão de públicos socialmente mais vulneráveis, o fato é que o Pronaf se manteve largamente orientado pela perspectiva de "modernização da agricultura familiar". Com efeito, por mais que o crédito fosse diferenciado, abarcando um segmento específico de agricultores, o mesmo manteve uma lógica produtivista e, por conta disso, passou a ser apropriado pelos agricultores mais capitalizados, ou seja, aqueles que não são objeto prioritário das ações de inclusão produtiva. Esta avaliação é ratificada por inúmeros críticos do programa:

O Pronaf vive sua fase de esgotamento como política pública massiva de ascensão social, mudança do modelo tecnológico em direção da agroecologia e universalização do acesso. Nos últimos anos o Pronaf foi sequestrado pela lógica bancária, transformou-se em formas de transferência de lucros para as indústrias de tratores e máquinas agrícolas, de agrotóxicos, de adubos químicos e multinacionais das sementes transgênicas. Afastou-se da lógica camponesa e fortalece o agronegócio da classe média rural e da indústria de venenos (LEAL \& GORGEN, 2015).

[...] a expansão do Pronaf funcionou como mola mestra para a disseminação da lógica técnica e econômica do agronegócio em meio às unidades familiares - por 
isso ganhando o nome de agronegocinho. Isso significou um aumento das áreas de monoculturas, a perda da diversidade dos sistemas produtivos, o emprego crescente de insumos comerciais (sementes, adubos químicos, agrotóxicos) e maquinário e equipamentos motomecanizados. Esse mergulho na modernização agrícola levou os agricultores familiares a uma crescente dependência dos mercados de capitais (bancos) e de mercados de produtos agrícolas dominados por agentes monopolísticos (empresas agroindustriais, grandes atacadistas, etc.) (WEID, 2010, p. 4).

Em relação à desconexão entre as políticas de segunda geração e inclusão produtiva é também reconhecida por Grisa e Schneider (2014, p.137), para quem "nem sempre de forma planejada e deliberadamente intencional, as políticas sociais e assistências acabaram tendo repercussóes sobre o desenvolvimento rural sob um viés que não é da inclusão produtiva ou pela ativação do mercado de trabalho". Outros trabalhos também chegaram à conclusão de que as políticas sociais tiveram dificuldades em integrar-se a iniciativas voltadas à inclusão produtiva (SOUZA, 2013; CAZELLA et al., 2016), apesar de que foram as primeiras políticas a tratarem de questóes sobre os aspectos da inclusão produtiva como vetor na mobilização das capacidades sociais e produtivas, no enfrentamento da pobreza e na emancipação dos beneficiários (SOUSA \& NIEDERLE, 2018).

De outro modo, o Pnae apesar de incentivar à produtividade dos agricultores familiares, não se tem menção ao termo inclusão produtiva na sua legislação. Já o PAA foi a única política na qual está explícita em sua normativa o fomento as ações de inclusão produtiva. De modo geral, as Compras Governamentais estão conectadas ao referencial próprio da terceira geração de políticas públicas que são guiadas pelas questões que perpassam à Segurança Alimentar e Nutricional. Seus efeitos são percebidos no incentivo a organização coletiva e formal dos agricultores, aumento da renda familiar, dinamização da economia local, valorização dos produtos regionais, garantia de inserção em novos mercados e contribuiçôes para a promoção da segurança alimentar. Por outro lado, a burocracia e a baixa organização dos agricultores são variáveis que dificultam a execução das políticas imersas nos mercados institucionais.

Houve baixo índice de respondentes $(43,5 \%)$ sobre o total de entrevistados que conhecem políticas públicas estaduais para a agricultura familiar. Dentre as políticas ditas estaduais pelos extensionistas rurais, como o Compra Direta e o Terra Forte, houve divergência de ideias, pois foram consideradas como políticas estaduais mesmo sua origem sendo de ordem federal. Isto porque não mencionaram qualquer política estadual que são direcionadas aos agricultores familiares e que são referências a este público, 
seja por não ter experiência na área, por desconhecê-la ou, ainda, por nunca ter ouvido alguém propagá-la. No geral, identificou-se a desconexão dos referencias das políticas analisadas em termos de inclusão produtiva em relação as ideias e práticas dos extensionistas.

O Compra Direta é visto como uma política essencial principalmente para os agricultores que estão iniciando alguma atividade produtiva "que muitas vezes vieram de uma atividade que eles eram empregados e depois passaram a ser os empreendedores rurais" (EX16, 2018). Outro ponto fundamental é que os referidos agricultores têm a garantia de que o seu produto, pelo menos em parte, pode ser vendido para o mercado institucional. Isto significa o primeiro passo para a viabilidade do negócio familiar. As impressões detalhadas deste mediador podem ser conferidas na narrativa abaixo.

O Compra Direta é um braço muito forte para o produtor rural que inicia a sua atividade e tem ali minimamente uma base de sustento porque é um Programa que compra num preço justo, num preço de mercado e lhe garante a venda. Quando um produtor nos procura na piscicultura, por exemplo, para perguntar por onde ele tem que começar a atividade, a gente costumeiramente fala que o primeiro passo é encontrar quem vai comprar o peixe dele. Então, para nós, é uma força muito grande você ter a condição pública, o governo poder adquirir esse produto, pelo menos em parte, então isso ajuda bastante (EX16, 2018).

O Programa Terra Forte tem por objetivo apoiar e promover a modernização de empreendimentos coletivos agroindustriais em Projetos de Assentamento da Reforma Agrária, criados ou reconhecidos pelo Incra, em todo o território nacional. Não se tem menção explícita sobre conter o termo inclusão produtiva na legislação de tal política. No Tocantins, o Programa Terra Forte é coordenado pela Secretaria da Agricultura, Pecuária e Aquicultura (Seagro). Foi mais uma política com um referencial divergente. No discurso abaixo, que reflete as ideias de atores distintos, determinado mediador em um primeiro momento não tinha identificado o Programa Terra Forte como política pública estadual de inclusão para a agricultura familiar, embora num segundo momento voltou a citá-la no decorrer da entrevista. Numa verificação minuciosa, infere-se que nem todos os mediadores que citaram o Programa Terra Forte, as relacionaram com a temática inclusão produtiva.

Olha, infelizmente eu não tenho como lhe informar, não existe uma política que nasceu no estado que trabalhe o fomento, a não ser né, hoje nós temos aí o Terra Forte que é um Programa que trabalha a aquisição de máquinas agrícolas para as Prefeituras. Isso eu posso destacar que realmente é algo que o Estado tem trabalhado que é o acesso as máquinas agrícolas para as Prefeituras para que elas possam fornecer serviços de mecanização em pequenas propriedades. Então, isso é algo que nós entendemos que é importante e que tem acontecido. Para 
além disso, algo que eu possa destacar a princípio não teria um outro destaque (EX01, 2018).

Desta narrativa, infere-se também que os mediadores tratam os beneficiários do referido Programa como todos os públicos da agricultura familiar, embora na finalidade do Terra Forte conste somente os assentados da reforma agrária, isso porque o Instituto Nacional de Colonização e Reforma Agrária (Incra) é a instituição que media as ações desta política.

Segundo alguns entrevistados, o Programa Terra Forte foi a única política para a agricultura familiar que o estado criou nos últimos anos. Tal ação respaldou na aquisição de máquinas e equipamentos agrícolas para o sistema de produção dos agricultores familiares, como trator, grade, roçadeira, plantadeira e pulverizador que foram comprados para todas as prefeituras municipais que abrange o Tocantins.

\section{CONSIDERAÇÕES FINAIS}

Ao buscar entender em que medida os referenciais que orientam as políticas de inclusão produtiva convergem (ou não) com as ideias e as práticas dos extensionistas implicados nos processos de tradução das políticas públicas para os diferentes grupos de agricultores familiares, pode-se perceber que, apesar da mudança no "referencial” das políticas governamentais com vistas a incorporar a noção de inclusão produtiva, chega-se a conclusão que, na maioria das vezes, não coincide, com as ideias e práticas dos extensionistas envolvidos nos processos de intervenção sociotécnica junto aos agricultores familiares, o que acentua as desconexões entre as intençôes das políticas de inclusão e seus efeitos.

De modo geral, verificou-se que no caso do Pronaf, os extensionistas a considera como uma política de "inclusão produtiva" com forte viés produtivista, embora em sua normativa não se faz menção. Trata-se, assim, de inferir que a própria política não se considera como política de inclusão. Por outro lado, as políticas sociais que se dizem de inclusão, não são reconhecidas pelos extensionistas, o que evidencia maior desconexão. Por sua vez, onde parece haver mais convergência são com as políticas de SAN, as quais tem um objetivo de inclusão mais claro e são reconhecidas pelos extensionistas como tal.

Isto nos leva a afirmar a existência de mais desconexóes do que conexóes entre o referencial das políticas públicas e as ideias e práticas dos mediadores. Por isso no título deste trabalho o prefixo "des" permanece entre parênteses no termo desconexão, pois das quatro políticas públicas mais citadas como promotoras de inclusão produtiva, apenas uma tem explicitamente em sua 
legislação aspectos voltados para este fim, neste caso o PAA. Nas demais políticas não há menção explícita em suas respectivas legislações. Postula-se, assim, que os extensionistas rurais sustentam ideias distintas sobre inclusão produtiva devido as políticas para a agricultura familiar serem orientadas por diferentes referenciais de inclusão, o que força os mediadores a articulá-las e torná-las coerentes para o público beneficiário.

\section{Agradecimentos}

Agradecemos ao financiamento obtido pelo edital do Cnpq/Sescoop n 07/2018.

\section{Referências}

ALVES, E. Agricultura familiar prioridade da Embrapa. Brasília: Embrapa, 2001. Disponível em: https://bit.ly/2rYjAEv. Acesso em 10 out. 2018.

AQUINO, J. R. \& NASCIMENTO, C. A. A grande seca e as fontes de ocupação e renda das famílias rurais no Nordeste do Brasil (2011-2015). In: $57^{\circ}$ Congresso De Economia, Administração e Sociologia Rural. Anais... Brasília/DF: SOBER, 2019. v. 1. pp. 1-16.

AQUINO, J. R. et al. Articulação de políticas para a superação da pobreza rural: um estudo das interfaces entre o Programa Bolsa Família e as políticas de inclusão produtiva no Nordeste e no Sul do Brasil. Revista Econômica do Nordeste, Fortaleza, v. 48, n. 4, pp. 155-173, 2017.

BLANDÓN, L. F. C. La narrativa de las políticas públicas en la jurisprudencia de la Corte Constitucional colombiana. Papel Político, Bogotá, v. 19, n. 2, pp. 435-458, 2014.

BRASIL. Lei $n^{\circ} 11.947$, de 16 de junho de 2009, 2009a. Disponível em: https://bit.ly/ 2CaewA2. Acesso em: 26 jan. 2019.

CAZELLA, A. A. et al. Políticas públicas de desenvolvimento rural no Brasil: o dilema entre inclusão produtiva e assistência social. Política \&Sociedade, Florianópolis, v. 15, n. especial, pp. 49-79, 2016.

COELHO, F. M. G. A arte das orientações técnicas no campo: concepções e métodos. Viçosa: Ed. UFV, 2005.
DEL GROSSI, M. Pobreza e extrema pobreza no Brasil rural. In: BUAINAIN, A. M. (org.). A nova cara da pobreza rural: desafios para as políticas públicas. Brasília: IICA, v. 16, 2012. pp. 319-334.

ESQUERDO, V. F. S. \& BERGAMASCO, S. M. P. P. Análise sobre o acesso aos programas de políticas públicas da agricultura familiar nos municípios do Circuito das Frutas (SP). Revista de Economia e Sociologia Rural, Brasília, v. 52, pp. 205-222, 2014.

FAVARETO, A. Entre chapadas e baixões do Matopiba: dinâmicas territoriais e impactos socioeconômicos na fronteira da expansão agropecuária no cerrado. São Paulo: Prefixo Editorial, 2019.

FRANÇA, D. M. C. Políticas públicas de educação para a população do campo: uma análise do Pronacampo a partir da abordagem cognitiva. 2016. Tese (Doutorado em Educação) - Curso de Pós-graduação em Educação, Universidade Federal do Rio Grande do Sul, Porto Alegre, 2016.

GAZOLLA, M. \& SCHNEIDER, S. Qual fortalecimento da agricultura familiar? Uma análise do Pronaf crédito de custeio e investimento no Rio Grande do Sul. Revista de Economia e Sociologia Rural, Brasília, v. 51, pp. 45-68, 2013.

GOTTWEIS, H. Rhetoric in policy making: Between logos, ethos, and pathos. In: FISCHER, F.; MILLER, G. (ed.). Handbook of public policy: Theory, politics and methods. Boca Raton: CRC Press, 2007, pp. 237-250. 
GRISA, C. Políticas públicas para a agricultura familiar no Brasil: produção e institucionalização das ideias. 2012. Tese (Doutorado em Ciências Sociais - Desenvolvimento Agricultura e Sociedade) - Curso de Pósgraduação em Ciências Sociais, Universidade Federal Rural do Rio de Janeiro, Rio de Janeiro, 2012.

GRISA, C. \& PORTO, S. I. Dez anos de PAA: As contribuições e os desafios para o desenvolvimento rural. In GRISA, C. \& SCHNEIDER, S. (org.). Políticas públicas de desenvolvimento rural no Brasil. Porto Alegre: Editora da UFRGS, 2015. p. 155-180.

GRISA, C. \& SCHNEIDER, S. Três gerações de políticas públicas para a agricultura familiar e formas de interação entre sociedade e Estado no Brasil. Revista de Economia e Sociologia Rural, Brasília, v. 52, pp. 125-146, 2014.

IBGE-Instituto Brasileiro de Geografia e Estatística. Pesquisa Nacional por Amostra de Domicílios, 2018. Disponível em: https://bit. ly/2TEaeJu. Acesso em: 10 mar. 2020.

JESSOP, B. The returns of the argumentative turn. Critical Policy Studies, London, v. 7, n. 4, pp.434-439, 2013.

JOBERT, B. \& MULLER, P. L'état en action. Paris: PUF, 1987.

KAGEYAMA, A. \& GRAZIANO DA SILVA, J. Os resultados da modernização agrícola dos anos 70. Revista Estudos Econômicos, São Paulo, v. 13, n. 3، pp. 537-559, 1983.

LEAL, M. \& GÖRGEN, F. S. A Hora e a Vez de um Programa Camponês. 2015.

LUKIC, M. R. \& TOMAZINI, C. As ideias também importam: abordagem cognitiva e políticas públicas no Brasil. Curitiba: Juruá, 2013.

MAJONE, G. Evidencia, argumentación Y persuasión en la formulación de políticas públicas. México: Fondo de Cultura Económica, 2005.

MEDINA, G; NOVAES, E. \& TEIXEIRA, S. A. Desenvolvimento local em territórios empobrecidos: possibilidades de inclusão social e produtiva de produtores rurais. Interações, Campo Grande, v. 18, n. 1, pp. 27-40, 2017.
MENESTRINHO, E. \& PARENTE, T. G. O estudo das territorialidades dos povos tradicionais. Brazilian Geographical Journal, Uberlândia, v. 2, pp. 1-19, 2011.

MIELITZ NETTO, C. G. A. A política agrícola brasileira, sua adequação e sua funcionalidade nos vários momentos do desenvolvimento nacional. In: BONNAL, P; LEITE, S. P. (org.). Análise comparada de políticas agrícolas: uma agenda em transformação. Rio de Janeiro: CIRAD/Mauad X, 2011. pp. 221-251.

MULLER, P. Esquisse d' une théorie du changement dans l' action publique: structures, acteurs e cadres cognitifs. Revue Française de Sciense Politique, Paris, v. 55, pp. 155-187, 2005.

MULLER, P. \& YVES, S. A abordagem cognitiva das políticas públicas. In: MULLER, P. \& SUREL, Y. (org.). A análise das políticas públicas. Pelotas: EDUCAT, 2002. pp. 44-50.

NAVARRO, Z \& PEDROSO, M. T. M. A agricultura familiar no Brasil: da promessa inicial aos impasses do presente. Revista Econômica do Nordeste, Fortaleza, v. 45, pp. 6-17, 2014.

NEVES, D. P. Políticas públicas: mediação e gestão de demandas sociais. Retratos de Assentamentos, Araraquara, v. 13, pp. 171-206, 2010.

NIEDERLE, P. A. Afinal, que inclusão produtiva? A contribuição dos novos mercados alimentares. In: DELGADO, G. C. \& BERGAMASCO, S. M. P. P. (org.). Agricultura familiar brasileira: desafios e perspectivas de futuro. Brasília: MDA, 2017, pp. 166-194.

NIEDERLE, P. A; FIALHO, M. A. V. \& CONTERATO, M. A. A pesquisa sobre agricultura familiar no Brasil - aprendizagens, esquecimentos e novidades. Revista de Economia e Sociologia Rural, Brasília, v. 52, pp. 9-24, 2014.

OLIVEIRA, N. M.; PIFFER, M. \& STRASSBURG, U. As vozes do território do Tocantins no processo de desenvolvimento regional. Revista Brasileira de Desenvolvimento Regional, Blumenau, v. 5, n. 2, pp. 25-52, 2017. Disponível em: https://bit.ly/3a7x3v5. Acesso em 03 dez. 2018. 
FAO-ORGANIZAÇÃO DAS NAÇÕES UNIDAS PARA A ALIMENTAÇÃO E A A GRICULTURA \& INCRA- INSTITUTO NACIONAL DE COLONIZAÇÃO E REFORMA AGRÁRIA. Diretrizes de Política Agrária e Desenvolvimento Sustentável. Brasília, Versão resumida do Relatório Final do Projeto UTF/BRA/O36, 1994.

PETARLY, R. R. et al. As possibilidades e desafios do Território Rural do Médio Araguaia para a inclusão produtiva. DRd- Desenvolvimento Regional em debate, Contestado, v. 6, n. 3, pp. 62-82, 2016.

PICOLOTTO, E. L. Os atores da construção da categoria agricultura familiar no Brasil. Revista de Economia e Sociologia Rural, Brasília, v. 52, pp. 63-84, 2014.

PLOEG, J. D. et al. On regimes, novelties, niches and co-production. In: WISKERKE, J. S. C. \& PLOEG, J. D. (ed). Seeds of transition. Assen: Royal van Gorcum, 2004, pp. 1-30.

RADAELLI, C. M. Récit (policy narrative). In: BOUSSAGUET, L; JACQUOT, S. \& RAVINET, $\mathrm{P}$ (ed). Dictionnaire de Politiques Publiques. 2. ed. Paris: Presses de Sciences Po, 2006. pp. 366-372.

REGO, W. L. \& PINZANI, A. Vozes do Bolsa Família: autonomia, dinheiro e cidadania. Unesp: São Paulo, 2013.

ROE, E. M. Narrative Policy Analysis: Theory and Practice. Durham/London: Duke University Press, 1994.

SABOURIN, E. Acesso aos mercados para a agricultura familiar: uma leitura pela reciprocidade e a economia solidaria. Revista Econômica do Nordeste, Fortaleza, v. 45، pp. 30-43, 2014.

SABOURIN, E. Origens, evolução e institucionalização da política de agricultura familiar no Brasil. In: DELGADO, G. C. \& BERGAMASCO, S. M. P. P. (org.). Agricultura familiar brasileira: desafios e perspectivas de futuro. Brasília: MDA, 2017. p. 265-291.

SABOURIN, E. \& GRISA, C. (Orgs.). A difusão de políticas brasileiras para a agricultura familiar na América Latina e Caribe. Porto Alegre: Escritos, 2018.
SCHMIDT, V. A. \& RADAELLI, C. M. Policy change and discourse in Europe: conceptual and methodological issues. West European Politics, London, v. 27, n. 2, pp. 183-210, 2004.

SCHNEIDER, S. Evolução e características da agricultura familiar no Brasil. Revista da ALASRU Nueva Epoca, Buenos Aires, v. 1, pp. 21-52, 2014.

SOLDERA, D. A instabilidade do referencial de políticas públicas para a agricultura familiar no Brasil: uma análise das narrativas dualistas. 2017.Dissertação (Mestrado em Desenvolvimento Rural) - Curso de Pós-graduação em Desenvolvimento Rural, Faculdade de Ciências Econômicas, Universidade Federal do Rio Grande do Sul, Porto Alegre, 2017.

SOUSA, D. N. Mediadores sociais e políticas públicas de inclusão produtiva da agricultura familiar no Tocantins: (des)conexões entre referenciais, ideias e práticas. 2019. Tese (Doutorado em Desenvolvimento Rural) Curso de Pós-Graduação em Desenvolvimento Rural, Faculdade de Ciências Econômicas, Universidade Federal do Rio Grande do Sul, Porto Alegre, 2019.

SOUSA, D. N. \& NIEDERLE, P. A. A produção científica brasileira sobre o que se entende por inclusão produtiva: um recorte temporal entre 2005 a 2016. Revista Desenvolvimento Social, Montes Claros, v. 1, pp. 15-32, 2018.

SOUZA, F. V. F. Assistência social e inclusão produtiva: algumas indagações. O Social em Questão, Rio de Janeiro, v. 17, n. 30, pp. 287298, 2013.

SUREL, Y. L'intégration européne par l'approche cognitive et normative des politiques publiques. Revue Française de Science Politique, Paris, v. 50, n. 2, pp. 235-254, 2000.

WANDERLEY, M. N. B. O campesinato brasileiro: uma história de resistência. Revista de Economia e Sociologia Rural, Brasília, v. 52, pp. 25-44, 2014.

WEID, J. M. Agricultura familiar: sustentando o insustentável? Disponivel em: https:// bit.ly/3fM3YKd. Acesso em 17 de mar. 2020. 